\title{
The spatiotemporal map of language production: towards a dynamic, non-sequential, and interactive neurobiological model
}

Citation for published version (APA):

Schuhmann, T. (2016). The spatiotemporal map of language production: towards a dynamic, nonsequential, and interactive neurobiological model. Language, Cognition and Neuroscience, 31(4), 511513. https://doi.org/10.1080/23273798.2015.1116701

Document status and date:

Published: 01/01/2016

DOI:

10.1080/23273798.2015.1116701

Document Version:

Publisher's PDF, also known as Version of record

Document license:

Taverne

Please check the document version of this publication:

- A submitted manuscript is the version of the article upon submission and before peer-review. There can be important differences between the submitted version and the official published version of record.

People interested in the research are advised to contact the author for the final version of the publication, or visit the DOI to the publisher's website.

- The final author version and the galley proof are versions of the publication after peer review.

- The final published version features the final layout of the paper including the volume, issue and page numbers.

Link to publication

\footnotetext{
General rights rights.

- You may freely distribute the URL identifying the publication in the public portal. please follow below link for the End User Agreement:

www.umlib.nl/taverne-license

Take down policy

If you believe that this document breaches copyright please contact us at:

repository@maastrichtuniversity.nl

providing details and we will investigate your claim.
}

Copyright and moral rights for the publications made accessible in the public portal are retained by the authors and/or other copyright owners and it is a condition of accessing publications that users recognise and abide by the legal requirements associated with these

- Users may download and print one copy of any publication from the public portal for the purpose of private study or research.

- You may not further distribute the material or use it for any profit-making activity or commercial gain

If the publication is distributed under the terms of Article $25 \mathrm{fa}$ of the Dutch Copyright Act, indicated by the "Taverne" license above, 


\section{The spatiotemporal map of language production: towards a dynamic, non-sequential, and interactive neurobiological model}

\section{Teresa Schuhmann}

To cite this article: Teresa Schuhmann (2016) The spatiotemporal map of language production: towards a dynamic, non-sequential, and interactive neurobiological model, Language, Cognition and Neuroscience, 31:4, 511-513, DOI: 10.1080/23273798.2015.1116701

To link to this article: https://doi.org/10.1080/23273798.2015.1116701

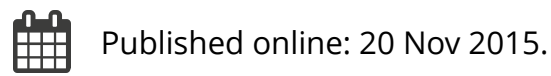

Submit your article to this journal ¿

Lll Article views: 207

Q View related articles ¿

View Crossmark data ¿

Citing articles: 1 View citing articles $\longleftarrow$ 


\section{The spatiotemporal map of language production: towards a dynamic, non-sequential, and interactive neurobiological model}

\section{Teresa Schuhmann}

Department of Cognitive Neuroscience, Faculty of Psychology \& Neuroscience, Maastricht University, 6200 MD Maastricht, The Netherlands

Since centuries scientists are struggling to unravel the complex relationship between the human brain and cognitive functions. The first more systematic neuropsychological studies in humans aiming at establishing a causal brain-cognition relationship were based on lesion or brain damage patients. It may not be a coincidence that the foundations of modern neuropsychology and cognitive neuroscience were laid by Paul Broca, in the $1860 \mathrm{~s}$, in the study of language production. Broca (1865) examined the brain of a patient who had been without any productive speech for many years. Broca documented this deficit and examined the brain of the patient post mortem. He identified a lesion in the left inferior frontal gyrus (IFG), now also known as Broca's region, based on which he inferred that it is this specific brain region that is necessary for language production. This functional localisation principle, according to which all functions of the mind can be attributed to neural activity in a specific location of the brain, is still at the heart of many neurocognitive models of human cognition. It was again, a pioneer in the science of language, Wernicke (1908), who acknowledged the fact that any complex cognitive function consists of different components that are carried out at different regions of the brain, interconnected to an organised activation network. This view widened the idea of localisation to interconnected localised functional networks.

Without doubt, language production is a very complex function. In fact, speaking may be one of the most complex human skills. A seemingly simple task like naming an object requires the well-orchestrated coordination of a series of sub processes including conceptual-semantic processing, lexical access, syntactic and phonological encoding, and articulation. The brain-language relationship has for long been subject of theoretical debate, conceptualisation, and empirical investigation across different scientific disciplines. Based on a meta-analysis of more than 80 neuroimaging studies, Indefrey and Levelt (2004) provided a detailed description of a possible spatiotemporal map of cerebral activations during speech production. According to this influential and very fruitful neurocognitive model, speech production first activates the occipito-temporal cortex for conceptual processing, then the left middle temporal gyrus (MTG) which is thought to be relevant for lexical access, followed by the posterior MTG (Wernicke's area) and the superior temporal gyrus (STG) for phoneme encoding, and the left IFG (Broca's area) for syllabification. Motor programming then takes place in preand post-central gyri.

This seminal work by Indefrey and Levelt (2004) has contributed tremendously to our understanding of the neurobiology underlying language production. For the first time, it provided a concrete neurocognitive model in which the various linguistic sub processes involved in speech production are distinguished in the framework of empirically testable spatiotemporal network predictions. Each single sub process is described to be carried out at a specific location in the brain as well as a specific moment in time during speech production. Inspired, guided, and fuelled by this model, several neuroscientific studies have been conducted, many of which report findings based on, for example, electrophysiological measurements or non-invasive brain stimulation experiments. These studies indeed seem to empirically support many of the spatiotemporal predictions provided by Indefrey and Levelt (2004).

In their opinion paper "The cortical dynamics of speaking; Present shortcomings and future avenues", Strijkers and Costa (2015) assess some of the inherent properties of this model by constructively questioning the proposed sequential activation cascade through distinct brain regions. Concretely, the authors raise three critical issues regarding a pure feedforward and serial conceptualisation of the spatiotemporal dynamics in word production. These three issues are discussed in the form of three open questions mainly intended to stimulate novel research endeavours in the area of speech production. First, the authors note that many of the studies supporting the model relied 
so heavily on the assumptions of the model for data interpretation, that sometimes an objective and independent empirical testing of the model was hindered ("Are the data supporting the model or is the model supporting the data?"). Second, the authors claim that word production is not a static, purely feedforwarddriven and context-invariant process, but instead systematically, and maybe even sub process-specifically, characterised by top-down influences such as intentions, expectations and experiences ("What is the role of top-down processing on the spatiotemporal dynamics?"). Finally, the authors raise the concern in how far an attempt of linking one-to-one each linguistic sub process to a specific brain region and processing time point, gives justice to the complexity of language production coding in the brain ("Can we map psycholinguistic stages onto the brain in a one-to-one fashion?").

In this timely, relevant and instructive opinion paper, the authors use these three open questions as a framework to plea for stronger "cross-talk between different domains of cognition (beyond the speech production tradition) and different domains of neuroscience (beyond the 'mapping' tradition)", with the ultimate aim of showing that the current spatiotemporal map of language production is "only a part, but not the whole story of how to integrate language, cognition and neuroscience" (Strijkers \& Costa, 2015).

I certainly support this plea and agree with the authors that the here presented critical issues indicate the necessity of continuously revising, updating, and adjusting the spatiotemporal predictions and the model in order to account for and eventually integrate new empirical findings. In fact, this is the beauty and the strength of such a concrete model proposed by Indefrey and Levelt (2004). By providing a series of testable spatiotemporal predictions, the Indefrey and Levelt model opened up the possibility for empirical support of these predictions as well as falsifications with the latter leading to necessary adjustments of our current conceptualisations.

My own research regarding the neurobiological mechanisms underlying speech production was also based on the Indefrey and Levelt model. In one of our studies, we combined magnetic resonance imaging (MRI) with a chronometric transcranial magnetic stimulation (TMS) design in order to empirically test and chart the exact time course of functional relevance of three distinct brain regions of the language network in the left hemisphere, namely (1) MTG, (2) STG (Wernicke's area) and (3) IFG (Broca's area), for successful speaking under controlled experimental conditions (Schuhmann, Schiller, Goebel, \& Sack, 2012).
Our multi-site chronometric TMS paradigm allowed us to empirically chart the relative time points of functional necessity in each of these network nodes. We could show that first MTG is relevant at around $225 \mathrm{~ms}$, followed by IFG (Broca's area) at around 300 ms, and finally STG (Wernicke's area) at around 400 ms. However, MTG showed to be functionally relevant at two distinct time points during picture naming, namely at an early stage (225 ms) and then again at a later stage $(400 \mathrm{~ms})$ during speech production. This second peak at around $400 \mathrm{~ms}$ temporally coincides with the functional relevance of posterior STG (Wernicke's area). Hence, although our design and hypotheses were based on the Indefrey and Levelt model, our findings only partly supported the model's predictions. For example, no second (late) functional relevance of MTG - as revealed in our study - is discussed in current speech production models, nor did the model predict that Wernicke's area is relevant only after Broca's area. This relative timing of IFG in fact makes the exact functional contribution of this area during word production less straightforward and clearcut as previously thought. In any case, these unexpected results forced us to post hoc interpret our findings in the light of the deviations from the model this study was based. We, for example, speculated that the early effect in left MTG may represent lexical retrieval (in accordance with the model), after which neural information is sent forward to IFG for subsequent phonological encoding. IFG in turn back-projects the phonologically encoded concept to left MTG while at the same time forward-projecting it to posterior STG, thus the speech comprehension system, for internal self-monitoring purposes. While remaining speculative, our empirical study certainly demonstrated that the Indefrey and Levelt model can be empirically put to the test using experimental designs that offer the possibility of revealing disagreeing results, and that based on this, attempts can be made to adjust and fine-tune some of the predictions and conceptualisations (Schuhmann et al., 2012).

Based on our own data using multi-site MRI-guided chronometric TMS, we clearly support the authors' notion that it is unlikely that language production follows a simple rigid and purely sequential processing principle in the brain. Instead, language production is very likely characterised by an interactive and dynamic non-sequential processing mechanism in which several brain regions are active at more than one time point, potentially because of system-inherent recurrent processing loops and/or because some of the central language regions are involved in more than one linguistic sub process. In fact, when looking at other domains in empirical brain research, it becomes evident that even simple perceptual functions are characterised by such 
interactive and recurrent activation patterns. It has, for example, been shown, that the conscious perception of visual movement is characterised by fast feedback projections from visual area V5 to area V1. Hence, activity appears to activate $\mathrm{V} 1$, is then sent forward to $\mathrm{V} 5$ and from there back-projected again to $\mathrm{V} 1$, as a neural mechanism underlying conscious visual motion perception (de Graaf, Herring, \& Sack, 2011; Pascual-Leone \& Walsh, 2001; Silvanto, Lavie, \& Walsh, 2005).

In the light of such complex interactive and recurrent activity loops underlying conscious visual perception, it seems naïve that a complex function such as language production would not require such principles but instead be simply computed by a rigid sequential cascade with fixed spatiotemporal characteristics. In this sense, the Indefrey and Levelt model represents a great starting point to now empirically fill-in the complex neural computations occurring in-between and across the predicted network nodes, including non-sequential, non-hierarchical, adaptive and contextdependent aspects of language production. This work is still in its initial stage and in their opinion paper Strijkers and Costa (2015) nicely review some of the recent findings supporting a more dynamic and interactive neural network underlying language production.

On a more general level, the authors also question to what extent it is meaningful trying to map psycholinguistic stages onto the brain in a one-to-one fashion. I very much agree with this general notion and would like to emphasise that this is a question relevant to cognitive neuroscience as a whole rather than a specific problem of the neurobiology of language. There are many cognitive psychological models trying to account for the complexity of human cognition, such as memory, attention, imagery, problem-solving, etc. These cognitive models define mental sub processes which are then linked in a certain interdependence and computational manner with each other in order to describe, explain, and predict human cognition. It remains to be seen whether some of these models and conceptualisations, when trying to translate them to the neurobiological level, that is, identify their neural substrate in the brain, turn out to not have such unique and specific neurobiological counterparts. In other words, it might very well be that some of these models describe cognitive sub functions that can only be differentiated on a psychological level as servants for a thinking framework among cognitive psychologists or psycholinguists. But on a neuronal level, the brain does not really care about such constructs, models, or labels, and the brain may in fact recruit identical or different neural structures for what we conceptualise as different or identical mental processes. Hence, what might be a very crucial and important semantic and conceptual difference for psychology and neurolinguistics, may for our brain in the end simply require the dynamic recruitment of complex and distributed parallel processing mechanisms not at all applicable to our modular theoretical framework. Coming back to the Indefrey and Levelt model, being exactly affected by this general complication of finding the relationship between brain and cognition, it is relevant to emphasise the importance of such models for stimulating research into the spatiotemporal dynamics underlying human cognition again. While being theoretically driven, it is of utmost importance to design empirical studies such that the data they produce can either be evidence in favour or against the predictions of a given model. After all, this is the beauty of empirical research.

\section{References}

Broca, P. (1865). Sur le siege de la faculte du langage articule. Bulletin de la Societé d'anthropologie, 6, 337-393.

de Graaf, T. A., Herring, J., \& Sack, A. T. (2011). A chronometric exploration of high-resolution 'sensitive TMS masking' effects on subjective and objective measures of vision. Experimental Brain Research, 209(1), 19-27. doi: 10.1007/ s00221-010-2512-z

Indefrey, P., \& Levelt, W. J. (2004). The spatial and temporal signatures of word production components. Cognition, 92(1-2), 101-144. doi: 10.1016/j.cognition.2002.06.001

Pascual-Leone, A., \& Walsh, V. (2001). Fast backprojections from the motion to the primary visual area necessary for visual awareness. Science, 292(5516), 510-512. doi: 10.1126/ science.1057099

Schuhmann, T., Schiller, N. O., Goebel, R., \& Sack, A. T. (2012). Speaking of which: Dissecting the neurocognitive network of language production in picture naming. Cerebral Cortex, 22(3), 701-709. doi: 10.1093/cercor/bhr155

Silvanto, J., Lavie, N., \& Walsh, V. (2005). Double dissociation of V1 and V5/MT activity in visual awareness. Cerebral Cortex, 15 (11), 1736-1741. doi: 10.1093/cercor/bhi050

Strijkers, K., \& Costa, A. (in press). The cortical dynamics of speaking: Present shortcomings and future avenues. Language, Cognition and Neuroscience. doi:10.1080/ 23273798.2015.1120878.

Wernicke, C. (1908). The symptom of aphasia. In A. Church (Ed.), Diseases of the nervous system (pp. 265-324). New York, NY: Appleton. 